\title{
Modeling of structural transformation kinetics in steels during their heat treatment
}

\author{
Liudmila Roslyakova ${ }^{1 *}$,VladimirPaukov ${ }^{1}$, Aleksandr Besedin ${ }^{1}$ and Vadim Suchilkin ${ }^{1}$ \\ ${ }^{1}$ Southwest State University, Kursk, Russia
}

\begin{abstract}
Analysis of carbide phase growth kinetics during carburizing of steel has been made in this paper, using experimental and calculated data obtained according to the classical theory of transformations in metals and alloys.
\end{abstract}

As thermodynamic calculations show, the carburizing of steels alloyed with chromium can be accompanied by the formation of an excess carbide phase in the diffusion layer, represented by special carbides and alloyed cementite. Experiments [1-3] show, the carbide phase is represented by isolated particles relatively uniformly distributed in a metallic (austenitic) matrix during carburization of the Fe-Cr-C system.

The analysis of structural transformation kinetics in steels was carried out in this work according to the classical theory of transformations in metals and alloys [4]. It follows that the growth rate of carbide particle nucleus in alloy steel is determined by processes at the interface, with diffusion being the dominant process. As the particle grows larger, it begins to grow at a rate equal to the rate of diffusion.

When analyzing the growth of carbide particles, only the diffusion of carbon can be taken into account, since the diffusion of interstitial elements proceeds at a rate several orders of magnitude higher than the number of substitution elements in solid solutions. For such a case (one-component diffusion), the usual mathematical description of the diffusion of one component is applicable without significant restrictions, it follows from the first and second Fick equations. In particular, the second Fick equation is applicable to describe the growth of spheroidized cementite particles:

$$
\frac{\partial C}{\partial t}=D\left(\frac{\partial^{2} C}{\partial r^{2}}+\frac{2}{r} \frac{\partial C}{\partial r}\right)
$$

where

$\mathrm{C}$ - is the concentration of carbon in the diffusion field of austenite,

$\mathrm{D}$ - is the average diffusion coefficient in the considered range of carbon concentrations in austenite (in this case, between supersaturated and saturated austenite),

$\mathrm{r}$ - is the coordinate along the normal to the phase boundary.

In order to solve Eq. (1) and find the distribution of carbon in austenite around the carbide particle, it is necessary to set additional (boundary) conditions. When growth is

\footnotetext{
* Corresponding author: roslyakova.rli@yandex.ru
} 
entirely controlled by diffusion, it can be assumed that the carbon concentration is constant and corresponds to the equilibrium concentration in the phase diagram in the region of austenite immediately adjacent to the growing carbide particle.

At the very beginning, after the nucleation of carbide phase centers, the interface has a noticeable curvature; therefore, the composition of austenite in equilibrium with carbide deviates from the values corresponding to the phase diagram due to the Gibbs-Thomson effect. However, this difference is significant only for particles whose size does not greatly exceed the radius of the critical nucleus. With further growth of particles, the GibbsThomson effect is not taken into account, which means: at the interface the concentration is always equal to the equilibrium concentration of carbon in austenite [5-6].

In the paper [7], a solution to Eq. (1) is obtained proceeding from the condition:

$$
C_{\gamma}^{\text {init }}=\lim _{\tau \rightarrow \infty} C_{\gamma}(\tau, t)
$$

which has the form:

$$
C_{\gamma}(\tau, t)=C_{\gamma}^{\text {init }}-\left(C_{\gamma}^{\text {init }}-C_{\gamma}^{\infty}\right) \frac{2 \frac{\sqrt{D t}}{\tau}-\sqrt{\pi} \operatorname{erf}(\tau / 2 \sqrt{D t})}{\frac{1}{\beta} \cdot \mathrm{e}^{-\beta^{2}}-\sqrt{\pi} \operatorname{erf} \beta}
$$

and:

$$
2 \sqrt{D t}=\rho(\mathrm{t}) / \beta
$$

where

$\mathrm{D}$ - is the carbon diffusion coefficient in austenite;

$\tau$ - is the coordinate along the normal to the phase boundary (austenide - carbide);

$\rho$ - is the radius of spherical carbide;

$C_{\gamma}^{\infty}$ - is the concentration of carbon in austenite at the interface with carbide (equilibrium concentration of carbon in austenite);

$\beta$ - is a coefficient, the value of which for values less than one, is determined from the expression:

$$
\beta=\sqrt{\frac{1}{2} \frac{C_{\gamma}^{\text {init }}-C_{\gamma}^{\infty}}{C_{c}-C_{\gamma}^{\infty}}}
$$

where

$C_{c}$ - is the carbon concentration in carbide.

For practical use of the given solution, it is necessary to have literature data on the coefficient $\beta$ and on the diffusion coefficient $\mathrm{D}$ of carbon in alloyed austenite, included in Eqs. (3) - (5), or to obtain them experimentally.

It can be determined the radius of a carbide particle growing in a supercooled into a carbide-austenitic region (between points $A_{3}$ and $A_{1}$ ), an austenite matrix, supercooled into a carbide-austenite region (between points $A_{3}$ and $A_{1}$ ) at small values from the expression (4), taking into account the equality (5).

The values of carbon equilibrium concentrations $C_{\gamma}^{\text {init }}, C_{\gamma}^{\infty}, C_{c}$, included in the expression (5) can be determined from pseudo-binary diagrams of state "doped iron carbon". It is necessary to have at least one of the experimentally determined values of $\rho, \beta$, $C_{\gamma}^{\text {init }}$ included in Eqs. (1) - (4) to use Eq. (1) to calculate the concentration curves of carbon in austenite around the carbide particles formed during carburizing. 
A number of heats of technically pure iron alloyed with chromium has been made. Carburizing is carried out at $920^{\circ} \mathrm{C}$ for 10 hours in a standard wood carburizer. The microstructure of one of the samples is shown in Fig. 1.

Analysis of carburized steel microstructures showed that cementite is the only carbide phase in the studied samples. Using metallographic analysis in the studied samples, the average radius $\rho$ of carbide particles is determined, the coefficient $\beta$ is calculated using Eq. (4), and the equilibrium carbon concentration is calculated using Eq. (5). The diffusion coefficient of carbon D in austenite is taken from the paper [4]. Table 1 shows the obtained values of $\rho, C_{\gamma}$ and $\beta$.

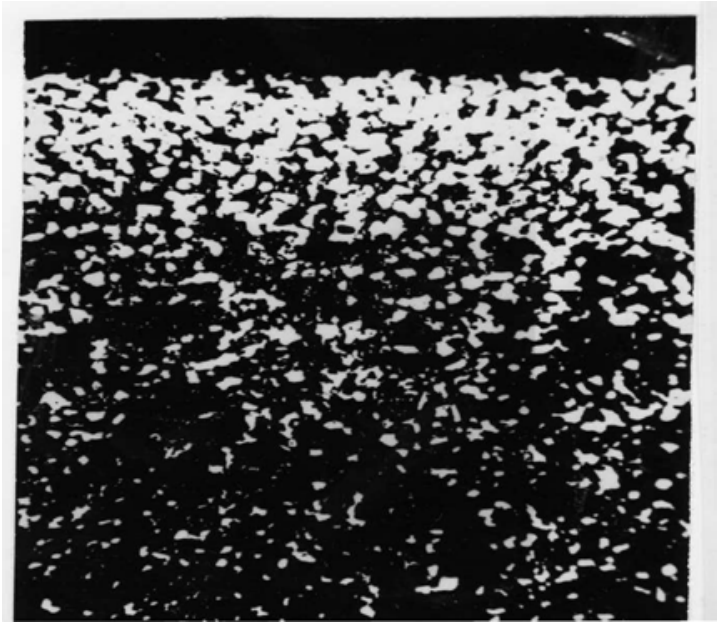

Fig. 1. Microstructure of steel with 3.1 at.\% Cr (x 500).

Table 1 shows that the obtained values of the $\beta$ coefficient are much less than one. It justifies the substitution of the experimental values of the coefficient $\beta$ into Eq. (4). It can also be seen from Table 1 that chromium slows down the diffusion growth of cementite particles significantly. Thus, an increase in the chromium content from 1.5 to 3.1 at\% reduces the average radius of carbides by about 2.5 times (from 8 to 3.3 microns).

Table 1. Chromium ifluence on the carbon content in cementite $\left(\mathrm{C}_{\mathrm{c}}\right)$, saturated and supersaturated austenite $\left(C_{\gamma}^{\text {equil }}, C_{\gamma}^{\text {init }}\right)$, constant $\beta$ and the size of the carbide particle $\rho$ after carbonization of alloyed iron at $920^{\circ} \mathrm{C}, 10 \mathrm{~h}$.

\begin{tabular}{|c|c|c|c|c|c|}
\hline \multirow{2}{*}{$\begin{array}{c}\text { Cr, at\% } \\
\text { in the alloy }\end{array}$} & \multicolumn{3}{|c|}{ Carbon content, at\% } & $\beta$ & $\begin{array}{c}\rho, \\
\text { microns }\end{array}$ \\
\cline { 2 - 5 } & $\mathrm{C}_{\mathrm{c}}$ & $C_{\gamma}^{\text {equil }}$ & $C_{\gamma}^{\text {init }}$ & & \\
\hline 1.1 & 25.29 & 4.50 & 4.515 & 0.019 & 9.6 \\
\hline 1.5 & 25.40 & 4.04 & 4.048 & 0.018 & 8 \\
\hline 3.1 & 25.73 & 3.02 & 3.025 & 0.010 & 3.3 \\
\hline
\end{tabular}

Substituting the obtained values of $\mathrm{D}, \beta, C_{\gamma}^{\text {init }}$ and the values $C_{\gamma}^{\infty}$ known from the literature [8] into Eq. (3), we have obtained the dependences $C(r, t)$. For steels with 1.5 and 3.1 at\% chromium, these dependences are shown in Fig. 2.

Figure 2 shows that the supersaturation of austenite with carbon is no more than 0.33 at\% C (after $10 \mathrm{~h}$ of carburizing at $920^{\circ} \mathrm{C}$ ). The length of the austenite field around the cementite particle (the length of the diffusion path) does not exceed $3 \mu \mathrm{m}$. With an increase 
in the chromium content in austenite, the degree of supersaturation of the latter with carbon and the length of the diffusion field decrease (the activity and diffusion coefficient of carbon in austenite decrease). It leads to a decrease in the growth rate of cementite particles and the distance between them, or to a decrease in the size of carbides with a large content of them. in an austenitic matrix.

From the presented experimental and calculated data, it follows that the effect of particles on the kinetics of their growth can be neglected as long as the distance between neighboring carbide particles exceeds double the length of the diffusion path (in the given conditions, $\sim 6 \mu \mathrm{m})$. The competition of growing carbides for excess carbon in supersaturated austenite and the mutual influence of carbide grains becomes significant after the diffusion fields of the particles begin to overlap to a noticeable extent.

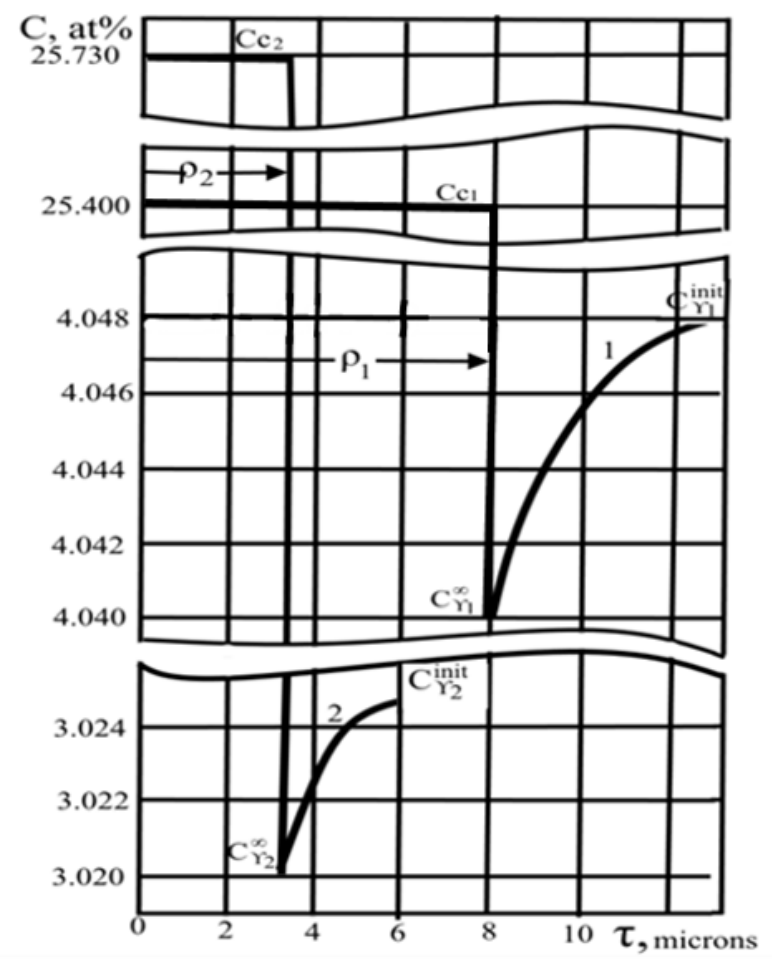

Fig. 2. Distribution of carbon in austenite around the cementite grain after carburizing with the content in austenite: 1-1.5 at.\% Cr; 2 - 3.1 at.\%.

This leads to a gradual decrease in the growth rate of carbide particles. Since in the carburizing process the supersaturation of austenite is constantly restored with carbon from the carburizer, the competition for carbon of neighboring carbides on the kinetics of their diffusion growth should manifest itself to a lesser extent compared to the usual precipitation of secondary carbides from supercooled austenite, i.e. without external carburization.

\section{References}

1. I.N..Roslyakov, V.I.Kolmikov, L.I.Roslyakova, J.Mechanical Eng.,No3, 62 (2011)

2. I.N.Roslyakov, D.V.Kolmikov, L.I.Roslyakova, J. Techonology of Metalls, No9, 22 (2011) 
3. L.I.Roslyakova, I.N.Roslyakov, A.G. Besedin, J.Nano-Electron Phys.,8No3, 03010 (2016)

4. B.Ya.Lyubov, Kinetic theory of phase transformations (M .: Metallurgy,1969)

5. L.I.Roslyakova, I.N.Roslyakov, Streng. Techn. and Coatings. No9(141), 26 (2016)

6. R Zenker, U Zenker, Surface Eng. 29 №1, 45 (1989)

7. L.I.Roslyakova, I.N.Roslyakov, L.P.Petrova, J.Nano-Electron Phys. 7 No4, 04097-104097-3 (2015)

8. L.I. Roslyakova, I. N.Roslyakov, J.Nano-Electron Phys. 6 No 3, 03047(2014) 